\title{
National Survey of Drug Information Centers' practice: Evidence-Based Medicine-Therapeutics Guidelines (EBM-TG) System at Ministry of Health hospitals in Saudi Arabia
}

\author{
Yousef Ahmed Alomi ${ }^{1} *$ (D), Saeed Jamaan Alghamdi², Radi Abdullah Alattyh ${ }^{2}$ \\ ${ }^{1}$ The Past General Manager of General Administration of Pharmaceutical Care, The Past Head, National Clinical \\ pharmacy and pharmacy practice, The Past Head, Pharmacy R and D Administration, Ministry of Health, Riyadh, \\ SAUDI ARABIA. \\ ${ }^{2}$ General Administration of Pharmaceutical Care, Ministry of Health, Riyadh, SAUDI ARABIA.
}

\begin{abstract}
Objective: To explore the practice at the National Survey of Drug Information Centers in Saudi Arabia with an emphasis on Evidence-Based Medicine-Therapeutics Guidelines (EBM-TGs) System at Ministry of Health hospitals. Methods: This is a 4-month crosssectional national survey of the Drug Information Services at $\mathrm{MOH}$. The survey contains 10 domains with a total of 181 questions designed by the authors. The questions were derived from the International Pharmaceutical Federation, American Society of HealthSystem Pharmacists best practice guidelines. The survey was distributed to 40 hospital pharmacies that run drug information services. In this study, the domain MedicationUse Evaluation System was explored and analyzed. It consisted of seven questions about the written policies and procedures and application methods for EBM-TG in the drug information centers. The data were analyzed through the Survey Monkey system. Results: The response rate was found to be around $88.88 \%$. According to the results, written policies and procedures for EBM-TGs existed only in $18(45 \%)$ hospitals and approximately $25-100 \%$ of the elements implementations. EBM-TG monitoring system is available live in only 17 (42.5\%) hospitals applying approximately $25-100 \%$ of the elements. According to our results, in only 18 (45\%) hospitals, the patients receive appropriate care due to EBM-TGs. There is evidence that the EBM-TG Indicators existed in only 19 (45.5\%) hospitals applying approximately $25-100 \%$ of the elements. Process for improving EBM-TG system exists in 20 (50\%) hospitals applying approximately $25-100 \%$ of the elements. Conclusion: There a poor application of EBM-TGs in the practice of drug information centers. Implementation of EBM-TG system improves patient outcomes which avoids unnecessary additional costs in the healthcare system. Key words: Drug Information Centers, Evidence-Based Medicine, Therapeutics Guidelines, Saudi Arabia.
\end{abstract}

\begin{abstract}
Received: 15-06-2018;
Accepted: 23-09-2018

*Correspondence to:

Dr. Yousef Ahmed Alomi

Email: yalomi@gmail.com

DOI: 10.5530/ijpcs.2018.7.6

Copyright: ( ) the author(s),publisher and licensee International Journal of Pharmacology and Clinical Sciences. This is an open-access article distributed under the terms of the Creative Commons Attribution Non-Commercial License, which permits unrestricted non-commercial use, distribution, and reproduction in any medium, provided the original work is properly cited.

This is an open access article distributed under the terms of the Creative Commons AttributionNonCommercial-ShareAlike 4.0 License
\end{abstract}

Access this article online

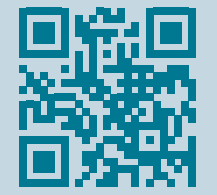

www.ijpcs.net

\section{INTRODUCTION}

The primary activity of the drug information center (DICs) is to answer drug information queries from the healthcare professionals and the public. ${ }^{1}$ During answering the question, the pharmacist needs to revise tertiary and then secondary references. If they do not find the answer, they switch to primary references. At each step, the pharmacist must read the reference carefully with critical appraisal of the topic and evaluate the literature. The new concept is more than the socalled evidence-based medicine. It can be used at each step of search to critically evaluate the topic before 
delivering the answer of the question. Furthermore, it can be used to set up therapeutic guidelines or management protocols for various diseases. The EBM concept implemented in the Kingdom of Saudi Arabia (KSA) through medicines and physician while in pharmacy field not existed. ${ }^{2-6}$ Several studies on DICs have been performed locally and they did not study the utilization of evidence-based reference or tool while answering queries or while designing guidelines. ${ }^{7,8}$ Other studies performed on a group of DICs have surveyed the network of DICs but have not mentioned anything related to the evidence-based medicine. ${ }^{9-12}$ The authors are unfamiliar with any investigations discussed with respect to the utilization of evidencebased medicine with DICs in Saudi Arabia or Gulf and Middle East countries. Moreover, it hard to find the studies worldwide in practice. Therefore, the goal of this survey is to explore EBM-TG system used in the drug information practice in Saudi Arabia.

\section{METHODS}

This is a 4-month cross-sectional national survey of Drug Information Services at Ministry of Health $(\mathrm{MOH})$. It contains 10 domains: Leadership and Practice Management, Medication Addition and Deletion System, Hospital Formulary System, Medication Safety System, Professional and Public Education, The Evidence-Based Medicine-Therapeutics Guidelines, Medication-Use Evaluation (MUE), Pharmacoeconomics System, Investigational Drug Services (IDS) and Professional Publications Services (PPPS, and Ethical and Legal Issue. It consisted of a total of 181 questions designed by the authors. They are derived from the International Pharmaceutical Federation (FIP, American Society of Health-System Pharmacists (ASHP) best practice guidelines, the international standard of Joint Commission of Hospital Accreditation. In addition to the local standards of Saudi Center of Health are Accreditation and Minimum Standards of DICs in Saudi Arabia. ${ }^{1,13-16}$ This survey was distributed to 40 hospital pharmacies that run drug information services. The basic information regarding the DICs services offered by the hospitals from the extensive records of General Administration of pharmaceutical care. This study was conducted in the year 2015. In this study, we explored and analyzed the EBM-TGs System. Table 2 shows the seven questions as per this domain. The data were analyzed by the Survey Monkey system.

\section{RESULTS}

The survey was distributed to $45 \mathrm{MOH}$ hospitals. Of them $40(88.88 \%)$ hospitals responded to the questions. Among the total responders, 35\% were large, $37.5 \%$ were medium size, and $17.5 \%$ were small size hospitals as well as $10 \%$ were National and Regional Drug Information Centers. Approximately 15 hospitals were accredited by CIBAHI and 8 hospitals were only accredited by Joint commission, whereas none of them were accredited by ASHP or Canada. Most responders were Saudi (38 $(95 \%))$ nationals. There were $28(70 \%)$ male and 12 (30\%) female responders (Table 1). Of all the responders, written policies and procedures for EBM-TGs existed only in 18 (45\%) hospitals applying approximately $25-100 \%$ of the elements. EBM-TG monitoring system is available live in only 17 (42.5\%) hospitals applying approximately $25-100 \%$ of the elements. Only 17 (42.5\%) hospitals performed intensive analysis of all EBM-TGs. Notification of treating physicians of EBM-TGs existed in only 17 (42.5\%) hospitals applying approximately $25-100 \%$ of the elements. Our results show that the patient receives appropriate care for EBMTG in only 18 (45\%) hospitals. Furthermore, EBM-TG indicators existed in only $19(45.5 \%)$ hospitals. Process for improving EBM-TG system existed in 20 (50\%) hospitals (Table 2).

\section{DISCUSSION}

The $\mathrm{MOH}$ started the strategic plan of healthcare system in 2010 and has shown several significant achievements. ${ }^{17}$ One of best achievement is the establishment of the evidence-based healthcare center. This project was founded with the collaboration of McMaster University, Canada. The center collaborates with the medical administrator and the assistant medical administrator at the $\mathrm{MOH}$. In addition, the center collaborates with non-MOH government organizations including universities, national guard institutions, military health organizations, and scientific societies. The primary goal of the center is to establish and distribute concepts of evidence-based medicines and national guidelines and protocol for diagnosis, management, and prevention of acute and chronic diseases among all healthcare professionals. ${ }^{18,19}$ The center also collaborates with Gulf s evidence-based medical center, the first center founded in Gulf area which is located at King Abdul-Aziz medical city. The $\mathrm{MOH}$ and Gulf center provides educational courses on evidence-based medicine. Till date, the $\mathrm{MOH}$ has released and published almost 20 diagnostics, management, and prevention of disease guidelines. ${ }^{19}$ 
Alomi, et al.: Evidence-Based Medicine at Ministry of Health hospitals in Saudi Arabia

\begin{tabular}{|c|c|c|c|c|c|c|c|c|c|c|}
\hline \multirow[b]{2}{*}{$\begin{array}{l}\text { Hospital size } \\
\text { (Number of } \\
\text { staffed beds) }\end{array}$} & \multirow[b]{2}{*}{$\begin{array}{c}\text { Number } \\
\text { of } \\
\text { hospitals }\end{array}$} & \multirow[b]{2}{*}{$\begin{array}{c}\% \\
\text { ages }\end{array}$} & \multicolumn{2}{|c|}{ Nationality } & \multicolumn{2}{|c|}{$\operatorname{Sex}$} & \multicolumn{4}{|c|}{ Accreditation } \\
\hline & & & Saudi & $\begin{array}{l}\text { Non- } \\
\text { Saudi }\end{array}$ & Male & Female & CIBAHI & $\mathrm{JCl}$ & Canada & ASHP \\
\hline \multicolumn{11}{|l|}{ Small } \\
\hline$<50$ & 1 & $2.5 \%$ & $1(2.5 \%)$ & $0(0 \%)$ & $1(2.5 \%)$ & $0(0 \%)$ & $0(0 \%)$ & $0(0 \%)$ & $0(0 \%)$ & $0(0 \%)$ \\
\hline 50-99 & 6 & $15 \%$ & $6(15 \%)$ & $0(0 \%)$ & $6(15 \%)$ & $0(0 \%)$ & $0(0 \%)$ & $0(0 \%)$ & $0(0 \%)$ & $0(0 \%)$ \\
\hline \multicolumn{11}{|l|}{ Medium } \\
\hline 100-199 & 7 & $17.5 \%$ & $7(17.5 \%)$ & $0(0 \%)$ & $6(15 \%)$ & $1(2.5 \%)$ & $0(0 \%)$ & $0(0 \%)$ & $0(0 \%)$ & $0(0 \%)$ \\
\hline 200-299 & 8 & $20 \%$ & $7(17.5 \%)$ & $1(2.5 \%)$ & $5(12.5 \%)$ & $3(7.5 \%)$ & $5(25 \%)$ & $2(10 \%)$ & $0(0 \%)$ & $0(0 \%)$ \\
\hline \multicolumn{11}{|l|}{ Large } \\
\hline 300-399 & 7 & $17.5 \%$ & $7(17.5 \%)$ & $0(0 \%)$ & $4(10 \%)$ & $3(7.5 \%)$ & $4(20 \%)$ & $2(10 \%)$ & $0(0 \%)$ & $0(0 \%)$ \\
\hline 400-599 & 7 & $17.5 \%$ & $6(15 \%)$ & $1(2.5 \%)$ & $5(12.5 \%)$ & $2(5 \%)$ & $6(30 \%)$ & $4(20 \%)$ & $0(0 \%)$ & $0(0 \%)$ \\
\hline $\begin{array}{l}\text { More than or equal } \\
600\end{array}$ & 0 & $0 \%$ & $0(0 \%)$ & $0(0 \%)$ & $0(0 \%)$ & $0(0 \%)$ & $0(0 \%)$ & $0(0 \%)$ & $0(0 \%)$ & $0(0 \%)$ \\
\hline \multicolumn{11}{|l|}{ Very Large } \\
\hline Medical Cities & 0 & $0 \%$ & $0(0 \%)$ & $0(0 \%)$ & $0(0 \%)$ & $0(0 \%)$ & $0(0 \%)$ & $0(0 \%)$ & $0(0 \%)$ & $0(0 \%)$ \\
\hline $\begin{array}{l}\text { National and Regional } \\
\text { Drug Information } \\
\text { Centers }\end{array}$ & 4 & $10 \%$ & $4(10 \%)$ & $0(0 \%)$ & $1(2.5 \%)$ & $3(7.5 \%)$ & $0(0 \%)$ & $0(0 \%)$ & $0(0 \%)$ & $0(0 \%)$ \\
\hline Missing No-Response & 0 & $0 \%$ & $0(0 \%)$ & $0(0 \%)$ & $0(0 \%)$ & $0(0 \%)$ & $20(50 \%)$ & $20(50 \%)$ & $20(50 \%)$ & $\begin{array}{c}20 \\
(50 \%)\end{array}$ \\
\hline Total Respondents & 40 & $100 \%$ & $38(95 \%)$ & $2(5 \%)$ & $28(70 \%)$ & $12(30 \%)$ & $20(50 \%)$ & $20(50 \%)$ & $20(50 \%)$ & $\begin{array}{c}20 \\
(50 \%)\end{array}$ \\
\hline \multicolumn{11}{|l|}{ Ownership } \\
\hline MOH-Hospitals & 40 & $100 \%$ & & & & & & & & \\
\hline Non-MOH Hospitals & 0 & $0 \%$ & & & & & & & & \\
\hline Privates & 0 & $0 \%$ & & & & & & & & \\
\hline
\end{tabular}

\begin{tabular}{|c|c|c|c|c|c|c|c|c|}
\hline \multirow{2}{*}{ Answer Options } & \multicolumn{5}{|c|}{ Scores* } & \multirow{2}{*}{$\begin{array}{l}\text { Rating } \\
\text { Average }\end{array}$} & \multirow{2}{*}{ Percent } & \multirow{2}{*}{$\begin{array}{l}\text { Response } \\
\text { Count }\end{array}$} \\
\hline & 1 & 2 & 3 & 4 & 5 & & & \\
\hline Written policy and procedure for EBM-TG. & 22 & 2 & 6 & 3 & 7 & 2.28 & 45.60 & 40 \\
\hline EBM-TG Monitoring system is available. & 23 & 4 & 6 & 3 & 4 & 2.03 & 40.60 & 40 \\
\hline Intensive analysis performed for all EBM-TG. & 23 & 2 & 7 & 4 & 4 & 2.10 & 42.00 & 40 \\
\hline Notification of treating Physician of EBM-TG. & 23 & 2 & 8 & 3 & 4 & 2.08 & 41.60 & 40 \\
\hline $\begin{array}{l}\text { There is evidence that the patient receives appropriate } \\
\text { care for EBM-TG. }\end{array}$ & 21 & 2 & 11 & 3 & 3 & 2.13 & 42.60 & 40 \\
\hline There is evidence that the EBM-TG Indicators. & 21 & 4 & 8 & 4 & 3 & 2.10 & 42.00 & 40 \\
\hline Process for improving EBM-TG system. & 20 & 6 & 6 & 5 & 3 & 2.13 & 42.60 & 40 \\
\hline answered question & & & & & & & & 40 \\
\hline skipped question & & & & & & & & 0 \\
\hline
\end{tabular}


The General Administration of pharmaceutical care collaborated with the center and participated with several clinical pharmacists during the establishment of the guidelines for evidence-based medicines. ${ }^{20-21}$ The pharmacy administration established evidence-based pharmacy based on the guidelines provided by the $\mathrm{MOH}$ center and on international literature as part of the DICs activities. The authors surveyed to explore EBM-TGs via DICs. Our results showed poor application and implementation of EBM-TGs among the investigated hospitals' DICs. Most of the literature did not mention anything in detail about the evidence-based medicine and may be one respondent stated the references of evidence-based medicine only. ${ }^{10}$ It is hard to compare our results with those of other studies. The drug information pharmacist needs education and training for evidence-based medicine and internal policy and policy for implementing the system at $\mathrm{MOH}$ hospital pharmacies in Saudi Arabia.

\section{CONCLUSION}

EBM-TGs are a new concept in the pharmacy field of DICs practice. Systemic implementation of EBM-TGs with education and training, close monitoring, and repeating the survey of the application of such new system improves DICs services and may prevent economic burden in the healthcare system at $\mathrm{MOH}$ hospitals in KSA.

\section{ACKNOWLEDGEMENT}

I want to thank all drug information pharmacist at all regions for their cooperation.

\section{CONFLICT OF INTEREST}

None.

\section{ABBREVIATIONS}

KSA, Kingdom of Saudi Arabia; $\mathrm{MOH}$, Ministry of Health; DIC, Drug Information Centers; IDS, Investigational Drug Services; PPPS, Professional Publications Services; EBM-TG, EvidenceBased Medicine-Therapeutics Guidelines; MUE, Medication-Use Evaluation; FIP, International Pharmaceutical Federation; ASHP, American Society of Health-System Pharmacists.

\section{ORCID ID}

Yousef Ahmed Alomi (D) https://orcid.org/0000-00031381-628X

\section{REFERENCES}

1. Ghaibi S, Ipema H GM. ASHP Guideline on The Pharmacist's Role in Providing Drug Information. Am J Heal Pharm. 2015;72(7):573-7.

2. Al- Ansary LA, Khoja TA. The place of evidence-based medicine among primary health care physicians in Riyadh region, Saudi Arabia. Fam Pract. 2002; 19(5):537-42.

3. Al-Baghlie N, Al-Almaie SM. Physician attitudes towards evidence-based medicine in eastern Saudi Arabia. Ann Saudi Med. 2004;24(6):425-8.

4. Al-Almaie SM, Al-Baghli N. Barriers facing physicians practicing evidence-based medicine in Saudi Arabia. J Contin Educ Heal Prof. 2004;24(3):163-70.

5. Al-Omari FK, Al-Asmary SM. Attitude, awareness and practice of evidence based medicine among consultant physicians in Western region of Saudi Arabia. Saudi Med J. 2006;27(12):1887-93.

6. Al-Musa HM. Knowledge, perceptions, attitude and educational needs of physicians to evidence based medicine in South-Western Saudi Arabia. Saudi Med J. 2010;31(3):308-12.

7. Alomi YA, Almudaiheem HY, Alarnous T, Alshurei S, Alsharafa A, Alzahrani $\mathrm{T}$, et al. Cost-efficiency of of national drug information center through ministry of healh hotline calling services (937) in Saudi Arabia: Application of American model. Value Health. 2015;18(7):A735.

8. YAA, Mudaiheem HA. National Drug Information Center Services through Ministry of Health Hotline Calling Center (937) in Saudi Arabia. Adv Pharmacoepidemiol Drug Saf. 2016;5(1).

9. Gallo GR, Wertheimer Al. An International Survey of Drug Information Centers. Drug Informalion J. 1985;19(1):57-61.

10. Rosenberg JM, et al. Current status of pharmacist-operated drug information centers in the United States. Am J Heal Pharm. 2004;61(19):2023-32.

11. Rosenberg JM, Schilit S, Nathan JP, Zerilli T, Mcguire H. Update on the status of 89 drug information centers in the United States. Am J Heal Pharm. 2009;66(19):1718-22.

12. Alamri S, Ali Al Jaizani R, Naqvi A, Ghamdi M. Assessment of Drug Information Service in Public and Private Sector Tertiary Care Hospitals in the Eastern Province of Saudi Arabia. Pharmacy. 2017;5(3):37.

13. Vernon G, Dvorkin L, Vidotti CCF, Woods D. Requirements for Drug Information Centres. FIP Pharmacy Information Section. 2005.

14. Medication Management (MM). In: National Hospital Standards [Internet]. $2^{\text {nd }}$ Edition. Saudi Central Board for Accreditation of Healthcare Institutions. 2015;194-211. Available from: http://www.cbahi.gov.sa

15. The Joint Commission. Comprehensive Accreditation Manuals. Joint Commission Resources. Available from: http://www.jcrinc.com/store/ publications/manuals/

16. Ministry of Health GPCD. Minimum standard of Drug Information Center in KSA [Internet]. Ministry of Health, Saudi Arabia. [Internet]. 2014. [cited 2017 Sep 24]. Available from: http://www.moh.gov.sa/depts/Pharmacy/ Documents/MINIMUM STANDARD OF DRUG INFORMATION CENTERS AT KSA.pdf

17. Ministery of Health. A Cheivements 2013 [Internet]. $1^{\text {st }}$ Edition. Riyadh, Saudi Arabia: Ministry of Health, Saudi Arabia. 2011;132-5. Available from: http://sgsminsk.by/_/media/Global/Documents/Technical Documents/ Technical Datasheets/SGS-PCA-SA-Datasheet SFDA-A4-EN-11-V2.pdf

18. Ministry of Health. The Saudi center for evidence based healthcare (EBHC) [Internet]. 2014. [cited 2017 Sep 24]. Available from: http://www.moh.gov. sa/endepts/Proofs/Pages/home.aspx

19. Ministry of Health. Clinical Practice Guidelines. The Saudi Center for Evidence Based Healthcare (EBHC) - Clinical Practice Guidelines [Internet]. 2014. [cited 2017 Sep 24]. Available from: http://www.moh.gov. sa/endepts/Proofs/Pages/Guidelines.aspx

20. Al-Hameed FM, Al-Dorzi HM, Abdelaal MA, Alaklabi A, Bakhsh E, Alomi 
Alomi, et al.: Evidence-Based Medicine at Ministry of Health hospitals in Saudi Arabia

YA, et al. The saudi clinical practice guideline for the prophylaxis of venous thromboembolism in medical and critically ill patients. Saudi Med J. 2016;37(11).
21. Al-Hameed FM, Al-Dorzi HM, Abdelaal MA, Alaklabi A, Bakhsh E, Alomi YA, et al. The saudi clinical practice guideline for the prophylaxis of venous thromboembolism in long-distance travelers. Saudi Med J. 2017;38(1).

Cite this article as: Alomi YA, Alghamdi SJ, Alattyh RA. National Survey of Drug Information Centers' practice: EvidenceBased Medicine-Therapeutics Guidelines (EBM-TG) System at Ministry of Health hospitals in Saudi Arabia. Int J Pharmacol. Clin. Sci. 2018;7(4):26-30. 